\title{
EL NACIMIENTO DE ESTEBANILLO GONZÁLEZ
}

En determinado momento de su paso por el tiempo literario español, se asocian en precario maridaje los géneros picaresco y bufonesco. Por género bufonesco entiendo yo la literatura escrita por bufones, o que tiene por protagonistas a bufones. Para bufones es toda la literatura, y por bufones fue planta exótica en la huerta de las letras ibéricas. Su ejemplo eximio, sin embargo, lo constituye la Crónica burlesca del emperador Carlos Vide don Francesillo de Zúñiga publicada en Barcelona en 1981, al cuidado de Diane Pamp de Avalle-Arce. Pero la Crónica de don Francesillo, a pesar de su inmensa popularidad, atestiguada por multitud de manuscritos, no se publicó hasta el siglo pasado. En nuestros siglos áureos la obra bufonesca impresa y de mucho éxito (tres ediciones en el siglo XVII) fue La vida $i$ hechos de Estevanillo González, hombre de buen humor, compuesto por él mismo (Amberes, 1646) ${ }^{1}$.

La autobiografía de este bufón ha desatado una tormentilla de truenos y relámpagos críticos que se ha centrado sobre el hecho de si nos hallamos ante una vida novelesca (ficción) o ante una vida circunstancial y genuina (historia). Defensor a ultranza de la historicidad de la Vida $i$ hechos lo fue en su momento Willis Knapp Jones y lo ha sido hoy en día el lamentado R. O. Jones,

${ }^{1}$ Sigo la ed. de Nicholas Spadaccini y Anthony N. Zahareas, Castalia, Madrid, 1978, aunque en algunas notas se deslizan talludos gazapos. Por ejemplo, en la 462 (Pedro Carbonero no tiene nada que ver con gitanos; véase mi Dintorno de una época dorada, J. Porrúa Turanzas, Madrid, 1978, pp. 353-369), o bien la 1364, que dice, en parte: 'Zagardoa, que mal azagaya: no es conocida esta especie de sidra, pero el nombre sirve para el equívoco con azagaya" (ocurre que en éuskera sagardoa es, precisamente, el nombre de "la sidra", por antonomasia). Las siguientes citas remiten a esta edición. 
de gran superioridad crítica sobre el otro Jones². En el extremo opuesto hay que colocar la tajante actitud de Marcel Bataillon, quien declaró: “Il restera, pour cela, à analyser la totalité de l'ouvrage (non une collection de détails) comme création littéraire et non autrement, en renonçant à la commodité trompeuse de l'illusion autobiographique" ${ }_{3}$. No se me ha ocurrido, en absoluto, meterme donde no me han llamado y enzarzarme en dicha polémica, pero sí quiero expresar mi opinión, que se debe tomar como la de un entretenido espectador.

Me parece que, dados los documentos accesibles, no quedan sino dos opciones por lo que respecta al sentido literal y base fundamental de la Vida $i$ hechos: o bien Estebanillo fue un bufón verdadero, quien al pulir sus chocarrerías llegó a ser escritor autobiógrafo y que al dar fin a la historia de su vida no volvió a escribir otro libro, tal cual Fernando de Rojas o el capitán Alonso de Contreras; o bien el autor de la Vida i hechos se escondió tras el seudónimo Estebanillo González. Esto hace de Estebanillo un apócrifo, un autor mentido que, en la realidad, actuó probablemente en el séquito del conde y duque Ottavio Piccolomini, a quien se dedicó la obra. La Vida i hechos sería, así, un tejido de hechos históricos entrecruzados por lugares comunes de la picaresca y por conocidas travesuras bufonescas, y esta amalgama llegó a ser la última novela picaresca del Siglo de Oro.

Debo insistir en que ni quito ni pongo rey, y que todo lo que quiero es ayudar a un más ceñido justiprecio de la Vida $i$ hechos como pieza literaria, ya sea historia o ficción. Por lo pronto y desde esta orilla, conviene apuntar que el propio autor (Estebanillo González, o quien fuese) nos brinda elementos de juicio para apreciar su obra dentro del marco concreto y estricto de la picaresca. Para colocar su obra de lleno dentro de dicha tradición literaria, el autor echa mano a recursos simples en su esencia, como ser el elogio de la vida picaresca, con lo cual, a ciencia y conciencia, se intenta identificar esta vida-obra con esa novelística a través del uso de uno de sus manidos tópicos. Así, por ejemplo, las ditirámbicas palabras hacia el comienzo de La ilustre fregona de Cervantes sir-

2 W. K. Jones, "Estevanillo González", RHi, 77 (1929), 201-245; R. O. Jones se refirió a la Vida como "casi con certeza una autobiografía auténtica", en la prestigiosa Historia de la literatura española que él mismo dirigió, véase t. 2: Siglo de Oro: prosa y poesía (siglos xvi y xvii), Ariel, Barcelona, 1974, p. 189.

${ }^{3}$ Marcel Bataillon, "Estebanillo González, bouffon pour rire", $H E M W$, 25-44, lo citado en el texto es de p. 43. La actitud de Bataillon provocó una serie de objeciones por parte de Franco Meregalli, "La existencia de Estebanillo González', RLit, 41 (1979), 55-67. 
ven de señas de identidad para las siguientes que se supone entonó Estebanillo:

Con el provecho de estos percances, ración y salario que ganaba, comía con sosiego, dormía con reposo, no me despertaban celos, no me molestaban deudores, no me pedían pan los hijos, ni me enfadaban las criadas, y así no se me daba tres pitos que bajase el Turco, ni un clavo que subiese el Persiano, ni que se cayese la torre de Valladolid. Echaba mi barriga al sol, daba paga general a mis soldados y me reía de los puntos de honra y de los embelecos del pundonor, porque a pagar de mi dinero, todas las demás son muertes, y sola es vida la del pícaro (I, pp. 252-53).

Después de esta declaración no puede sorprender que Estebanillo gallee con el pícaro más pintado, y que declare con tesón su estado de impenitencia final: "Volví a mi cuartel, planté el bodego y empecé a hacer lo que siempre había hecho, y lo mismo que hiciera agora si volviera a tal oficio'" (II, p. 322). El propio Guzmán de Alfarache, según unas afirmaciones iniciales de Mateo Alemán, "Declaración para el entendimiento deste libro', 1599, también escribió su vida en estado impenitente, pero sufriendo abrumador castigo por ello: "Él mismo escribe su vida desde las galeras, donde queda forzado al remo por delitos que cometió, habiendo sido ladrón famosísimo, como largamente lo verás en la segunda parte.' Pero al leer el final de esa segunda parte nos enteramos de que había sido muy otro el curso que Guzmán había imprimido a su vida, llevado por un firme arrepentimiento:

Exagerando el capitán mi bondad, inocencia y fidelidad, pidiéndome perdón del mal tratamiento pasado, me mandó desherrar y que como libre anduviese por la galera, en cuanto venía cédula de Su Majestad en que absolutamente lo mandase, porque así se lo suplicaban y lo enviaron consultado. Aquí di punto y fin a estas desgracias. Rematé la cuenta con mi mala vida. La que después gasté, todo el restante della verás en la tercera y última parte, si el cielo me la diere antes de la eterna que todos esperamos $\left(2^{a}\right.$, III, 9$)$.

Desde un prolongado estado de virtud Guzmán escribe su delictuosa vida ${ }^{4}$. Estebanillo González, por su parte, otea su pecaminosa vida como minero literario desde la torre de vigía de su

${ }^{4}$ Para ampliar mis observaciones, cf. el ceñido libro de JOAN ARIAs, "Guzmán de Alfarache": The Unrepentant Narrator, Tamesis Books, London, 1977. 
poco virtuosa casa de conversación en Nápoles (Vida i hechos, cap. 13). Y consecuente con todo ello, en el correr de su relato-vida Estebanillo declara a boca llena y con ufanía su impenitencia. En total y desenfadado encenagamiento, la vida de Estebanillo ha superado con creces la de Guzmán, el Pícaro por antonomasia.

Pero en todo momento este superpícaro, como se nos presenta Estebanillo, por designio vital o literario, tiene un oficio permanente, o casi, y con esto se supera a todo el género picaresco, cuyos protagonistas eran azotados a todo lo largo de sus vidas por el vendaval del desempleo, la falta de oficio permanente, y basta repensar el contenido de los siete tractados del Lazarillo para no tener que abundar en el tema. Este oficio, como se alardea desde el propio título de la Vida $i$ hechos, es el de un "hombre de buen humor', que, fisiología clásica aparte, es el de un bufón. Y por aquí volvemos a adentrarnos en lo más fundamental de esa centáurica autobiografía: la picaresca vida de un bufón (¿la bufonesca vida de un pícaro?) narrada por él mismo. Los dos géneros (la literatura bufonesca y la de pícaros) se acoquinan ante tal desolante de la imaginación creadora, si la Vida $i$ hechos es ficción, o ante las extremosidades de una vida, si lo narrado es historia.

Estebanillo se arrebuja y arreboza en su oficio de bufón, que le abriga de peores contingencias:

Echéme a los pies de Su Alteza Serenísima, dile las gracias por la recibida, y después de haberme oído algunas agudezas y contádole algunos chistes graciosos, quiso premiar mis servicios haciéndome grande de España, pues mandó que me cubriese, prometiéndome que con el tiempo me haría de la llave dorada de las despabiladeras. En efecto, me trató como a bufón, y me mandó dar de beber como a borracho. Pero aunque estuve a pique de cubrirme y de tomar posesión de tal oficio, lo dejé de hacer por ciertos sopapos y pescozadas que me dieron sus pajes con manos pródigas (I, pp. 274-275).

Glaro está que a Estebanillo le complace en sumo grado el exhibir su ambivalencia vital, ese vivir centáurico con que sigue a las famélicas tropas imperiales por los caminos de Europa. Le gusta declararlo a voces tronantes, como lo hace cuando, prisionero, comparece ante el Duque de Bouillon: "Mi nombre es Estebanillo González entre los españoles, Monsieur de la Alegreza entre la nación francesa. Mi oficio es el de buscón, y mi arte el de la bufa, por cuyas preeminencias y prerrogativas soy libre como novillo de concejo" (II, p. 330). Con esa declarada libertad Estebanillo se ha aupado lindamente a Mateo Alemán y su Guzmán, como 
hemos visto, y ahora lo hace, en forma alusiva, con don Francisco de Quevedo y su Buscón.

Esa misma libertad le ha permitido superar la picaresca al escribir desde el cuadrante de la bufonesca (su oficio vital), y la bufonesca al reptar a diario como pícaro buscón. Porque esa libertad le era negada al pícaro literario a nativitate, ya que heredaba una anonadante carga de criminalidad y de infamia al heredar la sangre de sus padres. Sobre esta infamia original (como el pecado) escribió brillantemente Marcel Bataillon en ocasión en que no tocó en absoluto el tema de la Vida $i$ hechos de Estebanillo González, lo que no debe caer en saco roto por lo que seguirá de inmediato ${ }^{5}$. Desde su origen, Lazarillo de Tormes está infamado por la criminalidad de los padres, por la efectiva persecución por justicia que sufre el padre y por el concubinato en que entra la madre. Guzmán de Alfarache lleva la infamia en la sangre y la dictamina el hecho de que su padre fue un judío repetidamente converso. Y la de Pablos de Segovia, para no entrar en más honduras, la determina la filiación de todos sus cuarteles con linajes de cristianos nuevos. Dentro de la interpretación mágica y tradicional de la importancia decisiva de la herencia de sangre, se debe hacer evidente que el pícaro lo es por un asfixiante determinismo apriorístico. El pícaro no puede reaccionar contra todo ello, y el autor se complace en acumular detalles acerca de la total vanidad de cualquier conato de lucha contra esa apabullante forza del destino, doblemente inevitable por llevarlo en la sangre.

Aquí entra en juego la novedad absoluta de la Vida $i$ hechos, y se entristece mi ánimo filológico al tener que reconocer que hasta ahora no se ha prestado la menor atención a este aspecto capital de la autobiografía de Estebanillo González. El caso es que Estebanillo no hereda ningún tipo de infamia. En su línea de desarrollo del Lazarillo al Buscón, las notas de infamia sobre el protagonista se habían acumulado con tal cerrazón que habían llegado a constituir un verdadero non plus ultra de posibilidades argumentales. Frente a esto Estebanillo innovará con sencillez y audacia. Dado que la infamia del protagonista se había agotado en cuanto resorte del argumento, la solución, de una sencillez perogrullesca, era presentar un protagonista que naciese al margen de toda nota de infamia ${ }^{6}$. Esto, con toda su deliciosa sencillez, es lo que se encar-

5 Pícaros y picaresca. "La picara Justina", Taurus, Madrid, 1969.

${ }^{6}$ Si la Vida $i$ hechos nos ofreciese una verdadera autobiografía, es interesante observar que el autor-protagonista acumula sobre su cabeza toda clase de denigrantes cualidades, menos la de una infamia a nativitate. 
ga de hacer Estebanillo González a partir del primer capítulo de su Vida $i$ hechos. Sus padres son dos gallegos de poca monta, mediocres en sus vicios y virtudes, pero un detalle de la personalidad de su padre atrae la atención de Estebanillo, quien lo presenta con delatora amplificatio. El padre, según nos informa Estebanillo:

Tenía una desdicha que nos alcanzó a todos los hijos, como herencia del pecado original, que fue ser hijodalgo, que es lo mismo que ser poeta; pues son pocos los que se escapan de una pobreza eterna o de una hambre perdurable. Tenía una ejecutoria tan antigua, que ni él la acertaba a leer, ni nadie se atrevía a tocarla, por no engrasarse en la espesura de sus desfloradas cintas y arrugados pergaminos, ni los ratones a roerla, por no morir rabiando de achaque de esterilidad (I, p. 149).

La lanza de la infamia a nativitate se embota para siempre ante la presencia de la hidalguía del padre. Lo que le viene por sangre ahora a Estebanillo es la hidalguía, no la infamia. Con todo cálculo, el autor ha abierto un verdadero abismo que separa su relato, desde su propio comienzo, de la picaresca tradicional y canónica. Pero la blasonada nobleza de Estebanillo, que le separa tan nítidamente de ios demás pícaros, le acerca, por lo demás, a cauces bien conocidos y transitados por la reducida literatura bufonesca española. Para no andar buscando pan de trastrigo sólo mencionaré el encabezamiento de una famosísima carta de don Francesillo de Zúñiga, astro mayor del género en España:

A nuestro muy desamado hermano el gran turco Solimán, sultán sage, gobernador de la casa de Meca, rey de la mayor parte de Asia, la mayor Siria y Egipto. Don Francés, por la divina clemencia, grande parlador, señor de los hombres de Persia y Arabia, destruidor de Meca, señor de Astensia y África, duque de Jerusalén por derecha sucesión, conde de los dos mares Rubén y Tiberiades, marqués de los Cuatro Vientos, consumidor de la seta mahomética, enemigo antiguo del Alcorán, falso profeta, archiduque de mancebos livianos, reformador de soberbios, conquistador de Asti, frontero de Berbería, campeador de paganos y de capas de terciopelo y de brocado y amigo de ducados de a diez y de a cuatro...

Y esta inacabable retahíla de títulos pausibles y de los otros, se remała con la hierática firma: "Vuestro extraño hermano, el conde don Francés" (ed. Diane Pamp de Avalle-Arce, pp. 145-147).

La hidalguía de su padre, sin embargo, Estebanillo la contrapesa deliberada, cuidadosa y continuamente con la cualidad de 
gallegos que tienen ambos padres, y el propio narrador, allí nacido. Porque lo gallego está visto con una lente de deformador aumento que acaba en sistemático menoscabo y ludibrio a la redonda de todo lo referente a Galicia. Así, por ejemplo, cuando Estebanillo se ve obligado a reconocer su galleguismo, lo hace con degradante fórmula y dice "ser, con perdón, gallego" (I, p. 146). O bien, más adelante, cuando regresa a su patria chica, éstas son las observaciones que se le ocurren:

Llegué a Pontevedra, villa muy regalada de pescado, adonde, siendo ballena racional, hice colación con medio cesto de sardinas, dejando atónitos a los circunstantes. Pasé de allí a Salvatierra, solar esclarecido de los Muñatones y patria de mis padres, que no oso decir que es mía, por lo que he referido de mi nacimiento y porque todos mis amigos, llegando a adelgazar este punto, me dicen: "Antes puto que gallego'" (I, p. 221).

Estas exageradas deformaciones acerca de una específica región española van acompañadas de ciertas características muy pro" pias del hombre Estebanillo, producto natural de dicha región. Claro está que todo esto apunta al completo deterioro de Galicia en esta presentación literaria. La característica principal de Estebanillo, y de la cual se ufana continuamente, es su afición desmedida al vino y demás bebidas alcohólicas que hace de su relato un tejido de extravagantes borracheras. En "Otro prólogo en verso" Estebanillo ensarta una horrible retahíla de vicios y pecados de los que se jacta. Entre ellos recae Estebanillo en lo de la borrachera y se dice ser, en forma autodefmitoria:

Mosquito de todos vinos, mono de todas tabernas, raposa de las cantinas, cuervo de todas las mesas (I, p. 139).

Claro está que la borrachera es sólo una de las serias tachas morales del carácter de Estebanillo, en la misma forma en que sólo es un aspecto de la literatura folklórico-tradicional anti-gallega desde los Siglos de Oro a nuestros días. Para ejemplificar con nuestra máxima autoridad en menesteres literarios, Cervantes, en la jornada tercera de su comedia La entretenida, hace que se insulte a un criado de esta manera:

Bodegón con pies, camine, que aquí no le conocemos; 
calle o pase, porque olisca

a lacayo y a gallego?

En realidad y en sustancia, la plétora de observaciones malévolas y capciosas de Estebanillo acerca de los gallegos atiende a trazar un retrato moral de Galicia y sus naturales, en este caso con las tintas más negras de la paleta. Y el retrato moral de una región o país y sus habitantes es lo que se denomina una etopeya. La práctica la podemos remontar a las caracterizaciones morales de las nacionalidades mediterráneas que nos brinda Heródoto en sus Historias. En España, en los años inmediatamente anteriores a los de Estebanillo, Cervantes hizo artístico e inteligente uso de las etopeyas en su Persiles y Sigismunda (1617, libro I) ${ }^{8}$. Para los mismos años en que se publicaba la Vida $i$ hechos, codificaba las etopeyas europeas don Diego Saavedra Fajardo desde su atalaya de embajador extraordinario en dos de las enjundiosas empresas de su Idea de un príncipe político-christiano, representada en cien empresas (1640). En la empresa LXXXI escribe:

La naturaleza, que en la variedad quiso mostrar su hermosura y su poder ${ }^{9}$, no solamente diferenció los rostros, sino también los ánimos de los hombres, siendo diversas entre sí las costumbres y calidades de las naciones. Dispuso para ello las causas, las cuales, o juntas obran todas en algunas provincias, o unas en éstas y otras en aquéllas. Los geógrafos dividieron el orbe de la tierra en diversos climas, sujeto cada uno al dominio de un planeta... Esta pues diversidad de climas, de colocaciones de provincias, de temples, de aires y de pastos, diferencian las complexiones de los hombres, y éstas varían sus naturales; porque las costumbres del ánimo siguen el temperamento y disposición del cuerpo.

La etopeya aunada a la teoría de los humores, fundamental para la fisiología de la época ${ }^{10}$, nos brindan un retrato de cuer-

7 Muchas más muestras de anti-galleguismo literario recogió Miguel HERRERo García, Ideas de los españoles del siglo xoii, Gredos, Madrid, 1966, pp. 202-225. Ello me exime de más citas.

${ }^{8}$ Algo de lo que escribo aquí sobre las etopeyas, ampliado y con las adecuadas referencias bibliográficas, lo hallará el lector en mis Nuevos deslindes cervantinos, Ariel, Barcelona, 1975, pp. 84-87.

${ }^{9}$ Saavedra Fajardo nos ofrece aquí una reelaboración del citadísimo verso de Serafino Aquilano (dell'Aquila), "Per troppo vriar Natura é bellas". La otra empresa a que me referí en el texto es la núm. xxxy.

${ }^{10}$ No olvidemos que ya desde el título de su vida Estebanillo tiene cuidado en anunciar que él es "hombre de buen humor", en su sentido etimológicofisiológico de la época. 
po entero de Estebanillo González mucho más veraz que el que mintió Lucas Vorsterman, según las cuentas de Marcel Bataillon. Estebanillo, o quien fuese, se amparó en ambos instrumentos retratistas para efectuar una liberación parcial del opresivo esquema de la picaresca tradicional. El nuevo protagonista no es un nuevo pícaro, hijo de padres infames y criminaloides, asestado indefectiblemente a seguir las huellas de los padres por la senda del crimen. Estebanillo es hijo de un hidalgo gallego, gallego él mismo, y carece de toda tacha infamante ab origine et a nativitate. Pero con muy hábil juego de manos Estebanillo nos escamotea la infamia (factor estructurante de la picaresca) y la sustituye por la burda y sangrienta comicidad del galleguismo. Y ahora este joven hidalgo gallego escogerá, para definirse con regusto, un oficio permanente, su oficio de bufón. Así, pues, Estebanillo elude un esquema literario (el de la picaresca), y alude a otro que se esfuma en un mar de chocarrerías y picardías, el de una bufonesca in fieri. Los datos que debemos recordar para medir exactamente la originalidad inmensa de la Vida i hechos de Estevanillo González, hombre de buen humor, es que este "último pícaro español" era un hidalgo gallego que optó por el honrado oficio de la bufonería.

Juan Bautista Avalle-Arce

Santa Ynez, California 